\title{
Meu Amigo Capaz - Design e Marcenaria Sustentável
}

\author{
My Able Friend - Design and Sustainable Woodworking
}

\author{
MAURO, Carlos Eduardo; Mestre em Educação; Univali - Universidade do Vale do Itajaí; \\ cadu@univali.br
}

BORBA, Carlos Eduardo; Especialista em Marketing; Univali - Universidade do Vale do Itajaí;

duda@univali.br

RAMOS, Marcos Roberto; Doutorando em Design; UFSC - Universidade Federal de Santa Catarina; marcos.roberto@univali.br

\section{Resumo}

O projeto "Meu Amigo Capaz Marcenaria Sustentável" oferta aulas de marcenaria básica para o aproveitamento de material já utilizado em construções e demolições, valorizando a capacidade de reciclagem. Destina-se à comunidade, promovendo ações de sustentabilidade com a comunidade carente e com os empresários do ramo de edificações e moveleiro demonstrando o potencial para a reutilização dos resíduos gerados pelos empreendimentos. Este projeto apresenta para a comunidade a forma de seleção, estaleiramento e separação por tipos e qualidades das madeiras capacitando os alunos na execução, gerenciamento, desenvolvimento e fabricação com aulas expositivas e práticas. Trabalha-se ainda com desenhos manuais onde os princípios de leitura e execução são atentamente analisados para que possam auxiliar os alunos na fabricação de novas peças. O projeto contempla os principais eixos para a produção de móveis de baixo custo e com material reutilizável, contribuindo para incrementar ações relacionadas a sustentabilidade promovendo ensino e melhorias sociais.

Palavras Chave: Sustentabilidade, Extensão social, Design de produto.

\begin{abstract}
The "My Friend Capable Sustainable Woodworking" project offers basic carpentry classes for the use of material already used in construction and demolition, valuing the recycling capacity. It is aimed at the community, promoting sustainability actions with the needy community and with the businessmen of the buildings and furniture industry, demonstrating the potential for the reuse of waste generated by the enterprises. This project presents to the community the form of selection, weaving and separation by type and qualities of the wood, enabling the students in the execution, management, development and fabrication with expositive and practical classes. We also work with manual drawings where the principles of reading and execution are carefully analyzed so that they can assist students in the fabrication of new pieces. The project contemplates the main axes for the production of furniture of low cost and with reusable material, contributing to increase actions related to sustainability promoting education and social improvements.
\end{abstract} Keywords: Sustainability, Social Outreach, Product Design. 


\section{Introdução}

A partir da interdisciplinaridade presente na Sustentabilidade, os conceitos provenientes de várias disciplinas formam um conjunto de ações para seu decorrer. O Design contemporâneo cada vez mais apresenta soluções e apoio para que a sustentabilidade se desenvolva com inovação e o bem-estar social observando as demandas da sociedade e do mercado.

Esses e outros conceitos do tema são implementados no projeto "Meu Amigo Capaz" observando a disciplina de processos industriais do Curso de Design Industrial, ressalta-se que a interdisciplinaridade de acordo com Fortes (2012, p. 1), "não anula as disciplinas, mas pede que as mesmas dialoguem entre si numa perspectiva educacional em busca de inovação". Desta forma surgiu a Extensão com intuito de auxiliar na sustentabilidade. Para contribuir com a extensão, o viés da educação faz parte do que buscasse transmitir e transferir aos alunos. Para Sachs (2004, p. 39), a educação é essencial para o desenvolvimento, pois contribui para o despertar cultural, a conscientização, a compreensão dos direitos humanos, aumentando a adaptabilidade e o sentido de autonomia, autoconfiança e autoestima. Não pode ser considerada uma panaceia, mas precisa fazer parte de um conjunto de políticas de desenvolvimento.

Nesta visão atua-se com o contexto da Universidade do Vale do Itajaí - UNIVALI, rodeada por um vasto mercado para produtos moveleiros de diversos tipos e com várias categorias mercadológicas visando o melhor bem-estar, uma vez que há diversidade de lojas pela cidade para fornecer composições de interiores. Nestas lojas, dentre os principais conceitos de produtos desenvolvidos, está o conceito de reutilização de material adequando seu viés de qualidade à sustentabilidade. Outro assunto de vital importância é que leva em conta o fato do mercado imobiliário estar em franca expansão com diversas demolições e construções novas. Com estas construções tem-se um excedente de material que pode ser reutilizado, porém em sua maioria são simplesmente descartados. Alguns sim são levados a lojas especializadas em madeiras descartáveis, reutilizáveis, principalmente quando estas são de demolições onde alguns materiais se encontram ainda em bom estado, mas a maioria que poderia estar sendo utilizada para a confecção de novas peças não são.

Assim, visa-se a iniciação ao desenvolvimento de projetos e construção de produtos moveleiros a nível básico e de iniciação, utilizando maquinários e materiais para construção de mobiliários. Nesta área de atuação contribui-se com a população de menor poder aquisitivo, dando a oportunidade de poderem ser até pequenos empresários ou formarem uma cooperativa na comunidade para um melhor desenvolvimento sociocultural e financeiro, levando em consideração ainda, a relação junto ao projeto de Economia Solidária da prefeitura Municipal. Ocorre a divulgação de ações e informações. Dentro desta filosofia a Economia solidária, trabalha um jeito diferente de produzir, vender, comprar e trocar, cooperando, fortalecendo um grupo, no bem de todos e no próprio bem. Inovadora alternativa de geração de trabalho e renda, resposta rápida a favor da inclusão social. Dentre elas estão práticas econômicas e sociais organizadas segundo o Portal do trabalhador do Ministério do Trabalho e Empregos (2012)

Este conceito Economia Solidária ainda pode ser entendido como conjunto de procedimentos e atividades econômicas, de produção, distribuição, consumo, poupança, organizados na forma de autogestão. Para tanto é necessário ter Cooperação, Autogestão, Dimensão Econômica e Solidariedade, vertentes estas que o projeto contemplaria junto a comunidade e também a alunos do Ensino Médio da Rede Municipal de Ensino. Hesselbein (2006) 
comenta que as comunidades do futuro estão cada vez mais integradas no âmbito da gestão, parcerias, marketing possibilitando assim ações diretas para a melhoria de sua população, sem descaracterizar sua cultura e seu acervo a cultura que estará sendo mais visado e aprofundado dentro das ações por elas recebidas.

\section{Apresentação do Projeto "Meu Amigo Capaz"}

Para Manzini (2003), o Design para a Sustentabilidade considera questões ambientais e o estudo do ciclo de vida no Design de Produto. Nesta visão a proposta de articular um aproveitamento de matérias práticas para implementar na comunidade ações que demonstrem o valor do Design na sociedade, além da possibilidade de inserção no mercado com produtos simples e matéria-prima que antes iria para o lixo e hoje passa a ser material de qualidade proporciona resultados para quem nunca imaginara fazer algo, equilibrando o sistema produtivo com as necessidades do bem estar social, otimizando a vida útil dos produtos, tendo como ponto de convergência a redução dos impactos ambientais. O autor Vezzoli $(2010$, p.45) desenvolve em seu livro um sentido mais amplo de sustentabilidade, que pode ser definido como "uma prática de Design, educação e pesquisa que, de alguma maneira, contribui para o desenvolvimento sustentável".

No desenvolvimento de produtos sustentáveis tem-se a problemática da duração desses produtos no meio desde a sua concepção até o seu descarte ou reaproveitamento/reciclagem e a questão da gestão de todo esse processo. A durabilidade, conforme Kazazian (2005, p.45) supõe uma gestão da obsolescência que pode ser objetiva (motivada pelos avanços técnicos) ou subjetiva (motivada pela aparência ditada pela moda). Aumentar com qualidade a duração da vida de um produto é uma estratégia oportuna para uma empresa.

\section{3 Área Geográfica}

O projeto contempla a região do entorno da Universidade do Vale do Itajaí - UNIVALI, estando sua visão nas comunidades mais carentes de três cidades, onde a população de renda per capita ativa e de menor poder aquisitivo e as aplicações de programas sociais são mais acentuados e possuem deficiência na formação acadêmica profissional.

\section{4 Áreas Temáticas}

A capacitação e qualificação profissional estão diretamente relacionadas à proposta de extensão visando um conjunto de ações junto à comunidade carente para inserir uma profissão ou qualificação aos recursos humanos existentes, porém não é dando trabalhos e nem assistência como as dos órgãos governamentais, para uma parcela de pequenos grupos que poderiam estar atuantes na economia do bairro e da cidade que por falta de oportunidade e desconhecimento das opções para fortalecimento de suas qualidades poderem estar atuando na economia local. $O$ objetivo do projeto é que com o viés das novas técnicas produtivas e gestão, seja possível levar aos integrantes que se interessem a estabelecerem uma ligação com a profissão e o empreendedorismo, mostrando as qualidades que podem ser obtidas com pequenas interferências em materiais em desuso, ao ponto de oportunizar vendas do seu trabalho 
desenvolvido. $\mathrm{O}$ fator humano trabalhado visa resgatar a autoestima de pessoas que poderiam estar em situações de risco social, onde muitas vezes são levados a atos exclusos e antissociais.

Desta forma acredita-se que o projeto contribui para uma qualidade social mais digna a comunidade no entorno a Universidade. Contempla-se então: Tecnologias, desenvolvimento produtivo, gerenciamento, empreendedorismo, qualidade, autoconfiança e mercado, qualificação, aumento da economia local, geração de renda, emprego, uso de tecnologias, planejamento e gestão que são o foco da extensão moveleira. Utilizando material não utilizados de construções, demolições e móveis descartados para todas estas linhas pragmáticas os alunos ampliam seus conhecimentos, através de recursos para que possam estar inseridos nas perspectivas intersociais e políticas públicas, incorporados pelos conhecimentos adquiridos fomentando as práticas de empreendedorismo e movimentação socioeconômica do local e das cidades, direitos estes que devem ter acesso.

\section{Objetivo Geral}

Oportunizar à comunidade, melhoria socioeconômica a partir de conhecimentos básicos para o desenvolvimento de projetos e construção de produtos moveleiros, utilizando matéria prima reaproveitada de construções e demolições com o conhecimento técnico científico e maquinário produtivo básico, formando profissionais na área moveleira.

\section{Objetivos Específicos}

Para atingir o objetivo geral, este projeto possui os seguintes objetivos específicos:

Apresentar à comunidade a proposta da extensão com exposições internas na universidade, em eventos e locais de grande circulação;

Possibilitar aos alunos compreender, ler e fabricar novos produtos;

Transmitir conhecimento na área de produção fabril, orçamento e acessórios de uso em movelaria, a partir da interpretação de desenhos para fabricação de móveis;

Capacitar acadêmicos dos cursos de Design para monitoria da extensão para a comunicação direta dentro da comunidade;

Organizar reuniões periódicas e participativas para aquisição de material (matéria-prima) junto à comunidade empresarial da região;

Disponibilizar aulas de desenho técnico e leituras com ensino gradativo em sala de aula laboratorial;

Proporcionar aulas práticas e teóricas sobre teorias e formas de processos construtivos, visando o uso de material reutilizado na construção moveleira;

Capacitar o aluno a utilizar os maquinários do laboratório de materiais e modelos e ferramentas manuais compatíveis no mercado para execução de seus trabalhos. 


\section{Procedimentos Metodológicos}

Com a finalidade de desenvolver um apoio à comunidade com material teórico e prático na área da construção de moveis utilizando material recuperado de resíduos de obras, construções e demolições, a extensão trabalhará em dois caminhos. O primeiro, está relacionado ao material teórico com aulas expositivas aplicadas na construção de móveis, e gerenciamento e empreendedorismo a partir de literaturas e desenhos. Na segunda parte tem-se as aulas práticas, em laboratório, aplicando as teorias e usabilidade dos equipamentos na confecção dos produtos, com apoio de material informativo organizado em apostilas com o procedimento de utilização dos maquinários e dicas construtivas. E por final exposição dos produtos desenvolvidos para serem vendidos aplicando as teorias de empreendedorismo e marketing, entre outras.

Neste projeto, aplica-se a metodologia proposta por Löbach (2001), a qual inicia a partir de um problema e vai até soluções práticas, passando por várias etapas desde sua inovação e aspectos sustentáveis indo além de aspectos relacionados ao artesanato como forma de aplicação em processos produtivos de baixas quantidades.

Para o desenvolvimento dos trabalhos, a equipe é formada por professores bacharéis na área de Design Industrial, que são responsáveis por coordenar o projeto e ministrar os conteúdoso, além de bolsistas dos cursos de design Industrial e arquitetura e técnico do laboratório de materiais e modelos do curso. Os equipamentos para fabricação são os disponibilizados no Laboratório de Materiais e Modelos. Para as aulas teóricas utilizam-se salas de aula da universidade e uso da biblioteca comunitária para pesquisas em literaturas pertinentes ao tema. Um pouco da estrutura para realização do projeto pode ser observado na figura 1, a seguir.

Figura 1 - Estrutura física para realização de aula teórica e prática

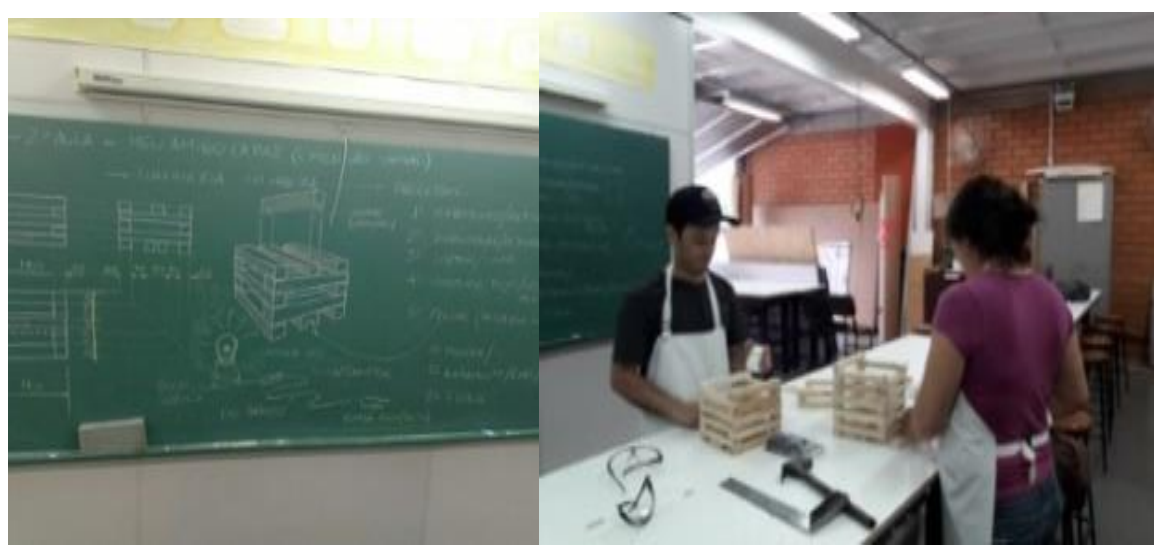

Fonte: autores (2018)

Nesta figura 1 temos um recorte de uma aula realizada, onde inicialmente foi exposto de maneira teórica o conceito e estrutura da peça a ser desenvolvida e posteriormente na prática foram trabalhadas as técnicas construtivas, utilizando-se do maquinário disponibilizado no laboratório. 


\section{Resultados}

Este projeto possui fluxo contínuo de entrada de alunos a partir da visibilidade da Universidade e também da parceria mantida com o Centro de Referência e Assistência Social (CRAS) do munícipio o qual está inserido. Durante o ano de 2017, por exemplo, foram organizados 5 grupos com média de 12 alunos. Destes, apenas 15\% desistiram antes de concluir todo o projeto.

Quanto ao resultado dos trabalhos desenvolvidos durante o ano de 2017, pode-se identificar vários tipos e níveis, pois as turmas eram bem heterogêneas com idades entre 19 e 65 anos e grau conhecimento, possibilitando níveis de complexidades de alguns produtos e acabamentos, com uso de ferramentas manuais e algumas industriais que facilitam o andamento das aulas, porém são correspondentes de maquinários industriais. Alguns dos resultados podem ser observados na figura 2 , a seguir.

Figura 2 - Alguns produtos realizados

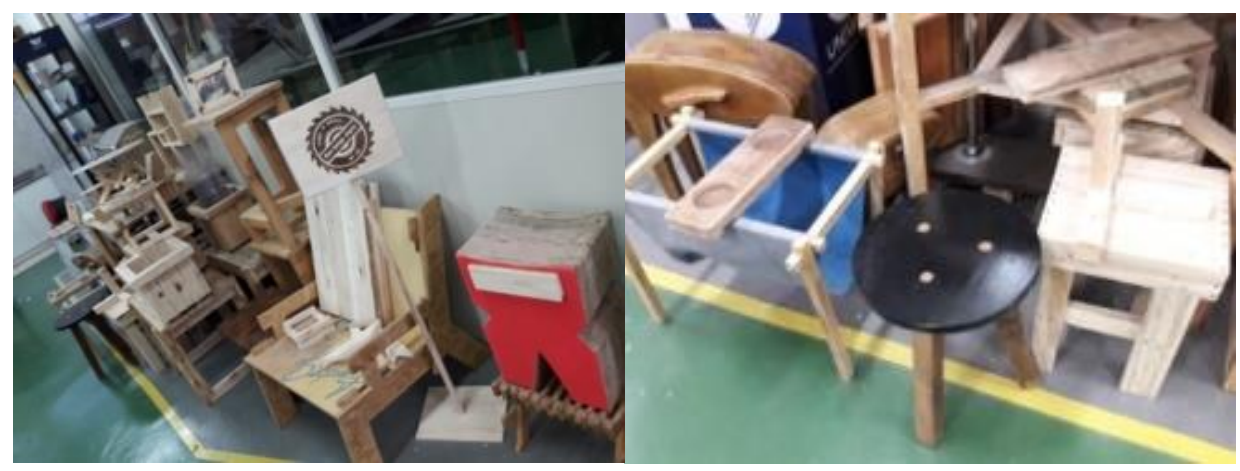

Fonte: Autores (2018)

Em síntese, os principais resultados estão associados ao aspecto do Design Social e se integrados ao grau de bem-estar econômico, social e político da comunidade através dos relacionamentos com diferentes parceiros e a sua estrutura e sistema social, que devem ser avaliados à luz dos interesses, sentimentos e necessidades do público-alvo. Considera-se impacto como sendo toda mudança duradoura e com efeitos de longo prazo. A ONU define projeto como "um empreendimento planejado que consiste num conjunto de atividades inter-relacionadas e coordenadas para alcançar objetivos específicos dentro dos limites de um orçamento e de um período de tempo dados". Então, com o projeto "Meu Amigo Capaz" pode-se compreender que a extensão proposta trabalha no esforço deliberado e planejado buscando promover condições e perspectivas de melhoria pessoal, social e econômica com finalidade de reduzir um pouco não somente a pobreza, mas o ingresso ou melhor o reingresso na vida social. A riqueza deste projeto está na transformação das coisas até então vistas como "inúteis" ou "descarte" em oportunidade e desenvolvimento social. Fazendo uma análise mais profunda, a avaliação de impacto transcende os conceitos de eficiência, eficácia e efetividade. É um processo contínuo e cabe em qualquer fase da execução a transformação social.

Podemos afirmar que o resultado obtido tem forte impacto não só na comunidade local, como também é possível mencionar a procura pelo projeto, por diferentes setores da sociedade e níveis sociais. As turmas em sua maioria são compostas por estudantes níveis médios e 
universitários, associações e prefeituras.

\section{Conclusão}

O projeto de extensão "Meu Amigo Capaz" mantém sua inspiração focada sempre na inserção social, utilizando matéria prima reciclável, madeiras de construção civil e palletes.

As aprendizagens feitas estabeleceram vários níveis de complexidade que foi determinada pela configuração dos membros envolvidos. Destaca-se participações de idades diferenciadas que contribuíram para a evolução e sinergia entre os alunos terminando em trabalhos de certo grau de qualidade além do esperado além do reconhecimento do projeto com várias entrevistas e exposições na Universidade. Estes aspectos refletem em uma lista de espera de 40 alunos para próximas turmas, demostrando a qualidade e o envolvimento de todos que estão participando. Há ainda muito trabalho por se fazer pensando na melhoria da forma de aplicação das atividades, direcionando para o desenvolvimento de uma apostila para desenvolvimento de trabalhos à distância e ampliação na quantidade de parceiros.

\section{Referências}

DeSACHS, I. Desenvolvimento: includente, sustentável, sustentado. Rio de Janeiro: Garamond, 2004.scrição e análise dos resultados qualitativos e quantitativos do projeto;

FORTES, C. C. Interdisciplinaridade: Origem, Conceito e Valor. Disponível em: <http://www3.mg.senac.br/NR/rdonlyres/eh3tcog37oi43nz654g3dswloqyejkbfuxkjpbgehjepnlzyl4 r3inoxahewtpql7drvx7t5hhxkic/Interdisciplinaridade.pdf>. Acesso em: 08/02/2018.

HESSELBEIN, F.; GOLDSMITH, M.; BECKHARD, R. O. Líder do futuro. São Paulo: Futura,2006.

KAZAZIAN, Thierry. Haverá a idade das coisas leves: design e desenvolvimento sustentável. São

Paulo: Editora SENAC, 2005. 193p.

LÖBACH, B. Design Industrial bases para configuração de produtos industriais. Editora Edgard Blücher Ltda. São Paulo 2001.

MANZINI, E.; VEZZOLI, C. O desenvolvimento de produtos sustentáveis. Trad. Astrid de Carvalho. São Paulo: Ed. USP, 2002.

Design para a inovação social e sustentabilidade - comunidades criativas, organizações colaborativas e novas redes projetuais. Rio de Janeiro: E-papers, 2008.

\section{Agradecimentos}

Agradecemos ao Centro de Referência e Assistência Social (CRAS), Universidade do Vale do Itajaí (UNIVALI), Programa UNIEDU Pós-Graduação e ao Programa de Pós-Graduação em Design (POSDESIGN/UFSC). 